\title{
A fuzzy multi-criteria decision-making method for purchasing life insurance in India
}

\author{
Chinmaya Ranjan Pattnaik ${ }^{1}$, Sachi Nandan Mohanty ${ }^{2}$, Sarita Mohanty ${ }^{3}$, Jyotir Moy Chatterjee ${ }^{4}$, \\ Biswajit Jana $^{5}$, Vicente García-Díaz ${ }^{6}$ \\ ${ }^{1}$ Department of Computer Science \& Engineering, ABIT College of Engineering, India \\ ${ }^{2}$ Department of Computer Science \& Engineering, ICFAI Foundation for Higher Education, India \\ ${ }^{3}$ Department of MCACPGS, Orissa University Agriculture Technology, India \\ ${ }^{4}$ Department of Information Technology, Lord Buddha Education Foundation, Kathmandu, Nepal \\ ${ }^{5}$ Department of computer SC\& engineering, Maulana Abul Kalam Azad University of Technology, India \\ ${ }^{6}$ Department of Computer Science, University of Oviedo, Spain
}

\begin{tabular}{l}
\hline Article Info \\
\hline Article history: \\
Received Feb 17, 2020 \\
Revised Mar 28, 2020 \\
Accepted May 15, 2020 \\
\hline
\end{tabular}

Keywords:

Fuzzy MCDM

Life insurance

Multi criterion decision-making

approach

TOPSIS

\begin{abstract}
Life insurance is an agreement between an insured and an insurer, where the insurer pays out a sum of money either on a specific period or the death of the insured. Now a day, People can buy a policy through an online platform. There are a lot of insurance companies available in the market, and each company has various policies. Selecting the best insurance company for purchasing an online term plan is a very complex problem. People may confuse to choose the best insurance company for buying an online term. It is a multi-criteria decision making (MCDM) problem, and the problem consists of different criteria and various alternatives. Here in this paper, a model has been proposed to solve this decision-making problem. In this model, a fuzzy multi-criteria decision-making approach combined with technique for order preference by similarity to ideal solution (TOPSIS) and it has been applied to rank the different insurance companies based on online term plans. The experimental results show that the life insurance corporation of India (LIC) gets the top rank out of 12 companies for purchasing an online term plan. A sensitivity analysis has been performed to validate the proposed model.
\end{abstract}

This is an open access article under the CC BY-SA license.

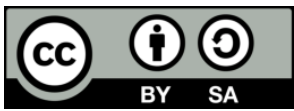

\section{Corresponding Author:}

Vicente García-Díaz,

Department of Computer Science,

University of Oviedo, Spain.

Email: garciavicente@ uniovi.es

\section{INTRODUCTION}

Future is rather unpredictable and uncertain. So, in this sea of uncertainties, due to imprecise activity in day to day life. As a result, financial loss and failure of desired event may occur. LI policy provides us with assurance that our family gets financial support and security even when one of us is not around anymore [1]. Those who avail LI are ensuring the safety of their loved dependent ones. In this case the company is at a risk of compensating the deceased as they are bounded by the contract $[2,3]$.

In this study, we are focusing on MCDM approach for selecting the best LI company for purchasing an online term policy [4]. MCDM is helps to select the best alternative among the set of alternatives and the methods of MCDM can be used in various field [5]. To define the decision-making parameters, we used fuzzy set theory. Fuzzy set theory was introduced by [6] and it support to vagueness and uncertainty in decision-making. In fuzzy set theory parameters are specified using linguistic terms such as very low, low, medium, high, very high, very poor, poor, fare good, very good instead of exact numerical values. 
Fuzzy logic may be useful to attempt at mechanization or formalization human capacities. First the capacity to converse, reason and settle on level headed choices in a domain having of imprecision, vulnerability, strife, and deficiency data. Second, the ability to play out a wide assortment of physical and mental assignments with no psychical estimation and calculation. There have some criteria for selecting the best insurance company among a set of companies. Criteria have some weighted values that are independent from each other. We evaluate the best insurance company alternative against the set of weighted criteria. We have chosen the company alternative for final implementation which is evaluating the best with respect to (w.r.t) all other criteria.

In 1997, [7] have discussed about the unfavourable selection in the purchase of insurance. In 1999, [8] has investigated after analyzed different decision-making strategies in different financial sectors problem related to insurance, banks, and financial firms, acquisition of firms, risk like bankruptcy risk, country risk and financial planning related problems. In this study, we suggested the different contributions of MCDM [9] in various financial problems and enlightened with possibility of structuring complex evaluation problems and have given different possible solutions. In 2011, [10] characterize the distance \& correlation measures for hesitant fuzzy information \& after that examined their characteristics in detail. In 2012, [11] have done the risk analysis and return analysis with the help of analytical hierarchy process (AHP) and ELECTRE III method in insurance linked securities (ILS) portfolios in portfolio management. Xu et al. [12] presented the ideas of entropy and cross-entropy for hesitant fuzzy information and investigated their attractive properties. In 2013, [13] have analyzed present and past status of LI sector and also discusses about the future strategies of the Indian insurance sector. In [14] presented another score function for positioning hesitant fuzzy elements (HFEs), which are the essential units of HFSs. In 2014, [15] have ranked Insurance companies especially in money back insurance policies domain with the help of classical AHP process. Khodamoradi et al. [16] have studied different insurance companies in Iran and have proposed a new hybrid method consisting DEMATEL and PROMETHEE II method using sample data from insurance companies listed in Tehran stock exchange for a period of 2010-2012 and applying the combined method, it was observed that Alborz Company has the highest and Dana Company has the lowest rate. In 2016, [17] introduced another aggregation method, to be specific, generalized Pythagorean fuzzy Einstein weighted averaging (GPFEWA) administrator and generalized Pythagorean fuzzy Einstein ordered weighted averaging (GPFEOWA) method under the Pythagorean fuzzy condition. In 2017, [18] studied the utilization of rough intelligence improvement methods and fuzzy ways for understanding the cooperative effects on financial performance. In 2018, [19] tried to present a fuzzy expert system for investigating the performance of insurance sector in Iran. Chiclana et al. [20] proposed another mining calculation dependent on animal migration optimization (AMO), called ARM-AMO, to diminish the quantity of association rules. Chatterjee et al. [21] give a best in class study over Bitcoin related advances and summarize different difficulties.

In 2019, [22] suggested a novice hybrid MCDM way to investigate service innovation methodologies for enhancing the tolerability of China's banking sector throughout the Fintech revolution. Jha et al. [23] audit the most recent advances on IoT with IoC from a class survey of distributed articles from 2009 to 2017. Jha et al. [24] call attention to a significant issue of stock market in regard to inclining situation of exchanges where data precision, exactness of communicating data \& vulnerability of qualities (shutting purpose of the day) are needed. Authors [25] expect to build up a system for MVNO in developing countries' telecommunication showcase as pursues: first, to do an intensive investigation of market and draft a possibility study for MVNOs in the telecommunications ("telecom") advertises in developing countries; and second, to create required guidelines for upgraded development openings in the telecom. Authors in [26] focus on the latest advancement over investigates concerning machine learning for big data analytic and various procedures with regards to modern computing for different applications. Authors [27] talk about the different utilizations of IoT in social insurance and related fields. Authors [28] were proposing an advanced system for phishing detection utilizing feature extraction \& classification of the mails utilizing SVM. Abbas and Chergui [29] have discussed about the impact of Pareto optimality concept on revised TOPSIS. Fahmi et al. [30] proposed a new variant of fuzzy TOPSIS based on triangular cubic hesitant fuzzy number (TCHFN). Several modified variants of fuzzy TOPSIS are used to solve the group decision making problem [31,32]. A system for Social Media Analytics dependent on MCDM (TOPSIS) model is suggested in [33] for social media information.

This paper is presented as follows. We have discussed about the fuzzy set theory in section 2 . We have discussed the propose model for ranking the insurance companies for purchasing online term policy in section 3. Numerical representation and sensitivity analysis (SA) have implemented in section 4. At last, we finish up the paper in section 5. 


\section{FUZZY SET THEORY}

The fuzzy sets are represented by linguistic terms that consist one or more linguistic variables, i.e. the linguistic variables have their possible states defined in a universe of discourse, represented by these linguistic terms. A fuzzy set 'F 'can be represented as,

$$
\mathrm{F}=\left\{\left(\mathrm{x}, \mu_{\mathrm{F}(\mathrm{x}))} \mid \mathrm{x} \in \mathrm{X}\right\}\right.
$$

where $\mu_{\mathrm{F}(\mathrm{x})}$ is the membership function (MF) for the fuzzy set $\mathrm{F}$. $\mathrm{X}$ is called as Universe of Discourse that is represented as linguistic values. Each element of $\mathrm{X}$ has membership grade among $0 \& 1$. MF are different types i.e. triangular, trapezoidal, sigmoid, Gaussian etc.

\subsection{Triangular MF}

A triangular MF shown in Figure 1 is represented by the three parameters $(a, b, c)$;

$$
\operatorname{trim} f(x: a, b, c)=\left\{\begin{array}{cc}
0, & x \leq a, \\
\frac{x-a}{b-a}, & a \leq x \leq b, \\
c-x & b \leq x \leq c, \\
c-b & c \leq x
\end{array}\right.
$$

Parameters $(\mathrm{a}, \mathrm{b}, \mathrm{c})$ are the real number and the value of these parameters specifies the $\mathrm{x}$ coordinates of the three corners of the triangular MF.

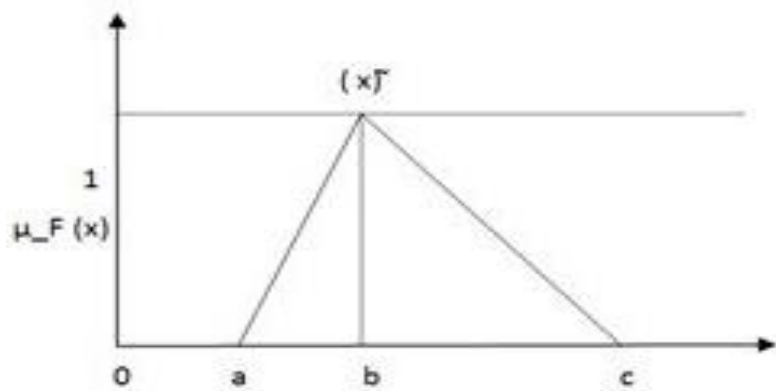

Figure 1. Triangular fuzzy number

\subsection{Distance between fuzzy triangular numbers}

Let $(\mathrm{x})=\left(\mathrm{x}_{1}, \mathrm{x}_{2}, \mathrm{x}_{3}\right)$ and $(\mathrm{y}) \tilde{=}=\left(\mathrm{y}_{1}, \mathrm{y}_{2}, \mathrm{y}_{3}\right)$ are triangular fuzzy numbers. The distance among two triangular fuzzy numbers computed by utilizing vertex method is given below.

$$
d(\tilde{x}, \tilde{y})=\sqrt{\frac{1}{3}\left[\left(x_{1}-y_{1}\right)^{2}+\left(x_{2}-y_{2}\right)^{2}+\left(x_{3}-y_{3}\right)^{2}\right]}
$$

\subsection{Linguistic variables}

Linguistic variable is described by a quintuple, which is consist a variable name, term set, universe of discourse, syntactic rule and semantic rule. In fuzzy set theory, transformation scale is needed to convert the fuzzy numbers from linguistic variable [15, 34-36]. Here we will apply a 1-9 transformation scale for rating the alternatives \& criteria. Linguistic variable for criteria ratings are represented in Table 1 and

\begin{tabular}{|c|c|}
\hline \multicolumn{2}{|c|}{ ratings } \\
\hline Linguistic variable & Membership function \\
\hline Very low (VL) & $(1,1,3)$ \\
\hline Low (L) & $(1,3,5)$ \\
\hline Medium (M) & $(3,5,7)$ \\
\hline $\operatorname{High}(\mathrm{H})$ & $(5,7,9)$ \\
\hline Very high (VH) & $(7,9,9)$ \\
\hline
\end{tabular}
linguistic term for alternatives ratings are represented in Table 2.

Table 1. Linguistic variables to define the criteria

\begin{tabular}{|c|c|}
\hline Linguistic variable & Membership function \\
\hline Very poor (VP) & $(1,1,3)$ \\
\hline Poor (P) & $(1,3,5)$ \\
\hline Fair $(F)$ & $(3,5,7)$ \\
\hline Good (G) & $(5,7,9)$ \\
\hline Very good (VG) & $(7,9,9)$ \\
\hline
\end{tabular}

Table 2. Linguistic variable to define the ratings of 


\section{PROPOSED MODEL FOR RANKING OF INSURANCE COMPANIES}

The proposed model for ranking of insurance companies consists of five different steps and these are depicted below.

\subsection{Process for election of insurance policy}

There are several types insurance policy is available in market such as term insurance plans, pension plan, health plan, endowment plan, child plan, money back plan. One of the popular plans is term insurance plan. Online term policy is a combine application of e-commerce and financial market. Now-a-days it is combined to the insurance sector and produces a new insurance product that is online term plan. There are lot of attractive facilities are available under this plan, where we can buy this type of plan directly without any help of an agent. In this paper we have chosen only the online term plan and finally ranking the insurance companies for purchasing an online term plan [13].

\subsection{Process for selection of criteria}

There are lot of criteria exist for recommending an insurance policy. We have chosen the 10 criteria that is described in Table 3. These criteria are taken from literature survey and consult with some experience person of this field. Criteria's are categorized in to two types i.e. cost criteria and benefit criteria. In cost criteria, lower value is preferable for alternative selection and for benefit criteria; higher value is more preferable for alternative selection [37]. In Table 3 , the criteria are denoted by $\mathrm{C}_{1}-\mathrm{C}_{10}$, here $\mathrm{C}_{4}$ and $\mathrm{C}_{6}$ are the cost criteria \& all other criteria are the benefit criteria.

Table 3. Criteria for recommendation of an insurance policy

\begin{tabular}{llc}
\hline \multicolumn{1}{c}{ Criteria } & \multicolumn{1}{c}{ Definition } & Criteria type \\
\hline Average claim ratio & Total number of death claim settled & Benefit \\
Entry age & Age of insured person at the beginning of policy & Benefit \\
Policy term & The benefit amount that is received by the policy holder or & Benefit \\
& nominee either death or contract stipulation & Cost \\
Maturity & Period of coverage provided by a policy & Benefit \\
Sum assured & Financial cost of a policy that is paid by the insured & Cost \\
Premium & Pre-decide amount, that insurer pay to the insured & Benefit \\
Premium payment term & Duration for the policy holder to pay the premium & Benefit \\
Premium payment frequency & Number of times to pay the premium & Benefit \\
Rebate on large sum assured & Discount on large sum assured & Benefit \\
Riders & Additional benefit that can be enhance the coverage & \\
\hline
\end{tabular}

\subsection{Process for selection of alternatives}

There are 24 LI companies in India under the IRDA [38]. At first, we have chosen some companies which has better claim ratio. It is an important criterion for an insurance company. It refers to the ratio of total number of death claim received $\&$ the total number of death claim settled. For an example, if a LI company receives 1000 death claim and settles 970 , then the claim ratio of this company would be $97 \%$. After that the claim ratio of each company has been evaluated for last 4 years (2011-2014) and then the average claim ratio has been calculated. Those companies which has more than $70 \%$ claim ratio have been considered. Finally, we have chosen 12 insurance companies which have online term plan facility. The alternatives of 12 insurance companies are ICICI $\left(A_{1}\right), \operatorname{LIC}\left(A_{2}\right), \operatorname{HDFC}\left({ }^{A_{a}}\right), \operatorname{SBI}\left({ }^{A_{4}}\right), \operatorname{MAX}\left({ }^{A_{5}}\right)$, BAJAJ ALLIANZ $\left({ }^{A_{6}}\right)$, BHARTI AXA $\left({ }^{A_{7}}\right)$, AEGON RELIGARE $\left({ }^{A_{9}}\right), \operatorname{RELIANCE}\left({ }^{A_{9}}\right)$, KOTAK MAHINDRA $\left({ }^{A_{10}}\right), \operatorname{CANARA} \operatorname{HSBC}\left({ }^{A_{11}}\right)$ and $\operatorname{AVIVA}\left({ }^{A_{12}}\right)$.

\subsection{Ranking Insurance companies using fuzzy TOPSIS}

We used a MCDM technique, called Fuzzy TOPSIS for choosing the best insurance company against some selected weighted criteria. TOPSIS helps to find the ideal possibility that is farthest from the negative ideal solution (NIS) and very near to the positive ideal solution (PIS). A NIS is consisting of the minimum values of each alternative and PIS is consisting of the maximum values of each alternative. The several steps of fuzzy TOPSIS are discussed as follows [35, 39-40].

- Step 1. Evaluation of performance assignment to the criteria and the alternatives

Let $n$ is a set alternatives, where $A=\left(A_{1}, A_{2}, A_{3}, \ldots, A_{n}\right), m$ is a set of criteria, where $C=$ $\left(C_{1}, C_{2}, C_{3}, \ldots, C_{m}\right)$ and $k$ is number of decision maker, where $D_{k}(k=1,2, \ldots, K)$. The value of alternatives is calculated against criteria. The weights for each criterion are represented by $c w_{i}(i=1,2,3, \ldots, m)$. The performance assignment of each decision maker for each alterative w.r.t each criterion is represented by $\tilde{P}_{k}=\tilde{y}_{i j k}(i=1,2,3, \ldots, m ; j=1,2,3, \ldots, n ; k=1,2,3, \ldots, K)$ with membership function $\mu_{\tilde{P}_{k}}(x)$. 
- Step 2. Calculate the aggregate fuzzy assignment for criteria and alternatives

Triangular fuzzy number is utilized to express the fuzzy assignment of all decision makers $\tilde{P}_{k}=$ $\left(x_{k}, y_{k}, z_{k}\right), k=1,2, \ldots, K$. The aggregated fuzzy rating is calculated as $\tilde{P}=(x, y, z)$, where;

$$
x==_{k}^{\min }\left\{x_{k}\right\}, \quad y=\frac{1}{K} \sum_{k=1}^{K} y_{k}, z={ }_{k}^{\max }\left\{z_{k}\right\}
$$

If the effective weight of the $k_{t h}$ decision maker and fuzzy assignment are $\widetilde{c w}_{i j k}=\left(c w_{j k 1}, c w_{j k 2}, c w_{j k 3}\right)$ and $\tilde{y}_{i j k}=\left(x_{i j k}, y_{i j k}, z_{i j k}\right)$ respectively, then the aggregated fuzzy ratings $\left(\tilde{y}_{i j}\right)$ of alternatives w.r.t each criterion are given by where $\tilde{y}_{i j}=\left(x_{i j}, y_{i j}, z_{i j}\right)$, where

$$
x_{i j}={ }_{k}^{\min }\left\{x_{i j k}\right\}, \quad y_{i j}=\frac{1}{K} \sum_{k=1}^{K} y_{i j k}, z_{i j}={ }_{k}^{\max }\left\{z_{i j k}\right\}
$$

The aggregated fuzzy weights $\left(\widetilde{c w}_{i j}\right)$ of each criterion are calculated as $\widetilde{c w}_{j}=\left(c w_{j 1}, c w_{j 2}, c w_{j 3}\right)$ where,

$$
c w_{j 1}={ }_{k}^{\min }\{c w\}, c w_{j 3}={ }_{k}^{\max }\left\{c w_{j k 3}\right\}
$$

- Step 3. Calculate the fuzzy decision matrix

Fuzzy decision matrix for the criteria and the alternatives is formed as bellows:

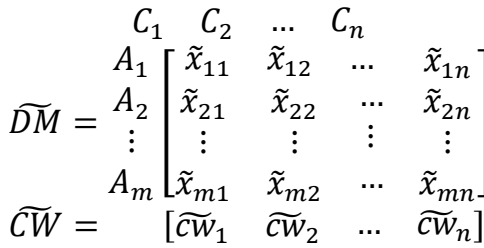

- Step 4. Fuzzy decision matrix should be normalized

Normalization should be required for transforming the raw data into normalized data. We normalized the fuzzy decision matrix is denoted by $\tilde{P}$, which is given by $\tilde{P}=\left[\tilde{p}_{i j}\right]_{m \times n}, i=$ $1,2, \ldots, m ; j=1.2 . \ldots n$, for cost criteria

$$
\tilde{p}_{i j}=\left(\frac{x_{j}^{-}}{z_{i j}}, \frac{x_{j}^{-}}{y_{i j}}, \frac{x^{-}}{x_{i j}}\right), \quad x_{j}^{-}={ }_{i}^{\min }\left(x_{i j}\right)
$$

and for benefit criteria,

$$
\tilde{p}_{i j}=\left(\frac{x_{i j}}{z_{j}^{*}}, \frac{y_{i j}}{z^{*}}, \frac{z_{i j}}{z_{j}^{*}}\right), z_{j}^{*}=_{i}^{\max }\left(z_{i j}\right)
$$

- Step 5. Calculate the weighted normalized fuzzy decision matrix

The weighted normalized fuzzy decision matrix $(W C)$ is calculated by multiplying the weights $\left(c w_{j}\right)$ of criteria with the normalized fuzzy decision matrix $\tilde{p}_{i j}$.

$$
\widetilde{W C}=\left[\widetilde{W c}_{i j}\right]_{m \times n}, i=1,2, \ldots, m ; j=1.2 \ldots . . n, \text { where } \widetilde{W c}_{i j}=\tilde{p}_{i j}(.) c w_{j}
$$

- Step 6. Calculate the fuzzy positive ideal solution (FPIS) and fuzzy negative ideal solution (FNIS)

The FNIS and FPIS of the alternatives are calculated as follows,

$$
\begin{aligned}
& F^{+}=\left(w c_{1}{ }^{+}, w c^{+}, \ldots, w c_{n}{ }^{+}\right) \text {where } w c_{j}{ }^{+}={ }_{i}^{\max }\left(w c_{i j 3}\right), i=1,2, \ldots, m ; j=1,2, \ldots, n \\
& F^{-}=\left(w c_{1}{ }^{-}, w c^{-}, \ldots, w c_{n}{ }^{-}\right) \text {where } w c_{j}^{-}={ }_{i}^{\min }\left(w c_{i j 1}\right), i=1,2, \ldots, m ; j=1,2, \ldots, n
\end{aligned}
$$

- Step 7. Calculate the distance from FNIS and FPIS for each alternative as follows:

The distance $\left(v_{i}{ }^{+}, v_{i}{ }^{-}\right)$of each alternative $i=1,2, \ldots, m$ from the FPIS and the FNIS is calculated

$$
\begin{aligned}
& v_{i}^{+}=\sum_{j=1}^{n} v_{t}\left(\tilde{t}_{i j}, t_{j}^{+}\right), i=1,2, \ldots, m \\
& v_{i}^{-}=\sum_{j=1}^{n} v_{t}\left(\tilde{t}_{i j}, t_{j}^{-}\right), i=1,2, \ldots, m
\end{aligned}
$$

where $v_{t}(\tilde{x}, \tilde{y})$ is the distance between two fuzzy numbers $\tilde{x} a n d \tilde{y}$. 
- Step 8. Calculate the closeness coefficient of each alternative

The closeness coefficient $\left(S_{i}\right)$ denoted the distances to the FPIS $\left(F^{+}\right)$and the FNIS $\left(F^{-}\right)$simultaneously. The $S_{i}$ of each alternative is computed as;

$$
S_{i}=\frac{v_{i}^{-}}{v_{i}^{-}+v^{+}}, i=1,2, \ldots, m
$$

- Step 9. Ranking of the alternatives

Ranking of alternatives are made according the value of closeness coefficient $\left(S_{i}\right)$ in decreasing order. Choose the best alternative which has heights $S_{i}$ value.

\subsection{Sensitivity analysis}

$\mathrm{SA}$ is a technique and it is used to determine the sensitiveness of the overall decision if we make changes in the input values. In this paper we have consider the assessment values of criteria as input [41]. It is also used to test the robustness of the model where uncertainties exist for different factors. We observe that how much effect on the decision if we slightly change the values of the weights of criteria? We used the SA on our model in the order to notice that the effectiveness of weights of the criteria in resolving the best insurance company for purchasing an online term.

\section{RESULTS AND DISCUSSION}

Let us consider that someone is interested to buy an online term policy. There are so many companies available. So problem is that how to determine the best company for buying a policy. A committee is formed which consist of three decision makers $D_{1}, D_{2}, D_{3}$ for choosing the best choice. The alternatives available for purchasing an online term policy is defined in Table 4.

There are several criteria used for purchasing an online term policy which is define in Table 3, that is Average claim ratio $\left(C_{1}\right)$, Entry age $\left(C_{2}\right)$, Policy term $\left(C_{3}\right)$, Maturity $\left(C_{4}\right)$, Sum assured $\left(C_{5}\right)$, Premium $\left(C_{6}\right)$, Premium payment term $\left(\mathrm{C}_{7}\right)$, Premium payment frequency $\left(\mathrm{C}_{8}\right)$, Rebate on large sum assured $\left(\mathrm{C}_{9}\right)$, Riders $\left(\mathrm{C}_{10}\right)$. Criteria $\mathrm{C}_{4}$ and $\mathrm{C}_{6}$ are the cost criteria \& rest of the criteria are benefit criteria.

The committee of 3 decision makers provide the linguistic judgment for the 10 criteria using the rating scale that is define in Table 1 and the 12 alternatives of insurance companies for each of the 10 criteria that is defined in Table 2. Linguistic judgment for the criteria and alternatives is defined in Tables 4-5.

By using (6), we calculate the aggregated fuzzy weight for each criterion. Let us take an example, the aggregated fuzzy weight for Average claim ratio $\left(C_{1}\right)$ is given by $\left(\widetilde{c w}_{j}=c w_{j 1}, c w_{j 2}, c w_{j 3}\right)$ where;

$$
c w_{j 1}={ }_{k}^{\min }\{7,7,7\}, c w_{j 2}=\frac{1}{3} \sum_{k=1}^{3}(9+9+9), c w_{j 3}={ }_{k}^{\max }\{9,9,9\} \widetilde{c w}_{j}=(7,9,9)
$$

This way we calculate the aggregated fuzzy weight for rest of all criteria and that is define in Table 4.

Table 4. Linguistic Judgment for the criteria and aggregated fuzzy weight for criteria

\begin{tabular}{lcccc}
\hline \multicolumn{1}{c}{ Criteria } & \multicolumn{2}{c}{ Weight of the Linguistic variable } & Aggregated fuzzy weight \\
\hline Average claim ratio & $(7,9,9)$ & $(7,9,9)$ & $(7,9,9)$ & $(7,9,9)$ \\
Entry age & $(5,7,9)$ & $(5,7,9)$ & $(7,9,9)$ & $(5,7.66,9)$ \\
Policy term & $(7,9,9)$ & $(7,9,9)$ & $(7,9,9)$ & $(7,9,9)$ \\
Maturity & $(7,9,9)$ & $(5,7,9)$ & $(7,9,9)$ & $(5,8.33,9)$ \\
Sum assured & $(5,7,9)$ & $(7,9,9)$ & $(7,9,9)$ & $(5,8.33,9)$ \\
Premium & $(7,9,9)$ & $(7,9,9)$ & $(7,9,9)$ & $(7,9,9)$ \\
Premium payment term & $(5,7,9)$ & $(5,7,9)$ & $(7,9,9)$ & $(5,7.66,9)$ \\
Premium payment frequency & $(3,5,7)$ & $(5,7,9)$ & $(5,7,9)$ & $(3,6.33,9)$ \\
Riders & $(3,5,7)$ & $(5,7,9)$ & $(3,5,7)$ & $(3,5.66,9)$ \\
Rebate on large sum $(3,5,7)$ assured () & $(3,5,7)$ & $(3,5,7)$ & $(3,5,7)$ & $(3,5,7)$ \\
\hline
\end{tabular}

we also calculate the aggregated fuzzy weight (AFW) for each alternative by using (6). Let us take an example, the aggregated fuzzy weight for alternative $A_{1}$ for criterion $C_{1}$ is

$$
\begin{aligned}
& \tilde{y}_{i j}=\left(x_{i j}, y_{i j}, z_{i j}\right) \\
& x_{i j}={ }_{k}^{\min }\{7,7,7\}, \quad y_{i j}=\frac{1}{3} \sum_{k=1}^{3}(9+9+9), z_{i j}={ }_{k}^{\max }\{9,9,9\}
\end{aligned}
$$

Similarly, we calculate the aggregated fuzzy weight for all the possibilities w.r.t the ten criteria and that is shown in Table 5. In Table 5, the $A R$ denotes the aggregated fuzzy ratings. 
Table 5. Linguistic judgment for the alternatives and aggregated fuzzy weight for alternatives

\begin{tabular}{|c|c|c|c|c|c|c|c|c|c|c|c|c|}
\hline & $A_{1}$ & $A_{2}$ & $A_{3}$ & $A_{4}$ & $A_{5}$ & $A_{6}$ & $A_{7}$ & $A_{8}$ & $A_{9}$ & $A_{10}$ & $A_{11}$ & $A_{12}$ \\
\hline$D_{1}$ & $(7,9,9)$ & $(7,9,9)$ & $(7,9,9)$ & $(7,9,9)$ & $(5,7,9)$ & $(5,7,9)$ & $(3,5,7)$ & $(5,7,9)$ & $(7,9,9)$ & $(3,5,7)$ & $(1,3,5)$ & $(1,3,5)$ \\
\hline$C_{1} \quad D_{2}$ & $(7,9,9)$ & $(7,9,9)$ & $(7,9,9)$ & $(5,7,9)$ & $(5,7,9)$ & $(5,7,9)$ & $(3,5,7)$ & $(5,7,9)$ & $(5,7,9)$ & $(3,5,7)$ & $(3,5,7)$ & $(1,3,5)$ \\
\hline$D_{3}$ & $(7,9,9)$ & $(7,9,9)$ & $(7,9,9)$ & $(7,9,9)$ & $(7,9,9)$ & $(7,9,9)$ & $(5,7,9)$ & $(3,5,7)$ & $(5,7,9)$ & $(5,7,9)$ & $(3,5,7)$ & $(3,5,7)$ \\
\hline$A R$ & $(7,9,9)$ & $(7,9,9)$ & $(7,9,9)$ & $(5,8.3,9)$ & $(5,7.6,9)$ & $(5,7.6,9)$ & $(3,5.6,9)$ & $(3,6.3,9)$ & $(5,7.6,9)$ & $(3,5.6,9)$ & $(1,4.3,7)$ & $(1,3.6,7)$ \\
\hline$D_{1}$ & $(7,9,9)$ & $(7,9,9)$ & $(3,5,7)$ & $(7,9,9)$ & $(5,7,9)$ & $(5,7,9)$ & $(5,7,9)$ & $(5,7,9)$ & $(5,7,9)$ & $(3,5,7)$ & $(5,7,9)$ & $(7,9,9)$ \\
\hline$C_{2} \quad D_{2}$ & $(7,9,9)$ & $(5,7,9)$ & $(5,7,9)$ & $(5,7,9)$ & $(7,9,9)$ & $(7,9,9)$ & $(7,9,9)$ & $(7,9,9)$ & $(5,7,9)$ & $(5,7,9)$ & $(3,5,7)$ & $(5,7,9)$ \\
\hline$D_{3}$ & $(5,7,9)$ & $(5,7,9)$ & $(5,7,9)$ & $(7,9,9)$ & $(5,7,9)$ & $(7,9,9)$ & $(5,7,9)$ & $(5,7,9)$ & $(5,7,9)$ & $(5,7,9)$ & $(5,7,9)$ & $(5,7,9)$ \\
\hline$A R$ & $(5,8.3,9)$ & $(5,7.6,9)$ & $(3,6.3,9)$ & $(5,8.3,9)$ & $(5,7.6,9)$ & $(5,8.3,9)$ & $(5,7.6,9)$ & $(5,7.6,9)$ & $(5,7,9)$ & $(3,6.3,9)$ & $(3,6.3,9)$ & $(5,7.6,9)$ \\
\hline$D_{1}$ & $(5,7,9)$ & $(5,7,9)$ & $(1,3,5)$ & $(5,7,9)$ & $(3,5,7)$ & $(5,7,9)$ & $(7,9,9)$ & $(1,3,5)$ & $(5,7,9)$ & $(5,7,9)$ & $(1,3,5)$ & $(3,5,7)$ \\
\hline$C_{3} \quad D_{2}$ & $(5,7,9)$ & $(5,7,9)$ & $(3,5,7)$ & $(3,5,7)$ & $(5,7,9)$ & $(3,5,7)$ & $(5,7,9)$ & $(1,3,5)$ & $(3,5,7)$ & $(5,7,9)$ & $(1,3,5)$ & $(5,7,9)$ \\
\hline$D_{3}$ & $(5,7,9)$ & $(5,7,9)$ & $(1,3,5)$ & $(5,7,9)$ & $(5,7,9)$ & $(5,7,9)$ & $(7,9,9)$ & $(1,3,5)$ & $(5,7,9)$ & $(7,9,9)$ & $(1,1,3)$ & $(5,7,9)$ \\
\hline$A R$ & $(5,7,9)$ & $(5,7,9)$ & $(1,3.6,7)$ & $(3,6.3,9)$ & $(3,6.3,9)$ & $(3,6.3,9)$ & $(5,8.3,9)$ & $(1,3,5)$ & $(3,6.3,9)$ & $(5,7.6,9)$ & $(1,2.3,5)$ & $(3,6.3,9)$ \\
\hline$D_{1}$ & $(7,9,9)$ & $(3,5,7)$ & $(5,7,9)$ & $(3,5,7)$ & $(5,7,9)$ & $(5,7,9)$ & $(3,5,7)$ & $(5,7,9)$ & $(5,7,9)$ & $(3,5,7)$ & $(5,7,9)$ & $(7,9,9)$ \\
\hline$C_{4} \quad D_{2}$ & $(5,7,9)$ & $(3,5,7)$ & $(5,7,9)$ & $(5,7,9)$ & $(7,9,9)$ & $(3,5,7)$ & $(5,7,9)$ & $(3,5,7)$ & $(5,7,9)$ & $(1,3,5)$ & $(7,9,9)$ & $(5,7,9)$ \\
\hline$D_{3}$ & $(5,7,9)$ & $(5,7,9)$ & $(3,5,7)$ & $(3,5,7)$ & $(5,7,9)$ & $(3,5,7)$ & $(5,7,9)$ & $(5,7,9)$ & $(7,9,9)$ & $(3,5,7)$ & $(5,7,9)$ & $(7,9,9)$ \\
\hline$A R$ & $(5,7.6,9)$ & $(3,5.6,9)$ & $(3,6.3,9)$ & $(3,5.6,9)$ & $(5,7.6,9)$ & $(3.5 \cdot 6,9)$ & $(3,6.3,9)$ & $(3,6.3,9)$ & $(5,7.6,9)$ & $(1,4.3,7)$ & $(5,7.6,9)$ & $(5,8.3,9)$ \\
\hline$D_{1}$ & $(5,7,9)$ & $(7,9,9)$ & $(5,7,9)$ & $(5,7,9)$ & $(5,7,9)$ & $(5,7,9)$ & $(3,5,7)$ & $(3,5,7)$ & $(3,5,7)$ & $(5,7,9)$ & $(5,7,9)$ & $(3,5,7)$ \\
\hline$D_{2}$ & $(7,9,9)$ & $(5,7,9)$ & $(5,7,9)$ & $(5,7,9)$ & $(7,9,9)$ & $(7,9,9)$ & $(5,7,9)$ & $(5,7,9)$ & $(3,5,7)$ & $(3,5,7)$ & $(3,5,7)$ & $(3,5,7)$ \\
\hline$D_{3}$ & $(7,9,9)$ & $(5,7,9)$ & $(7,9,9)$ & $(3,5,7)$ & $(7,9,9)$ & $(7,9,9)$ & $(5,7,9)$ & $(5,7,9)$ & $(3,5,7)$ & $(5,7,9)$ & $(5,7,9)$ & $(5,7,9)$ \\
\hline$A R$ & $(5,8.3,9)$ & $(5,7.6,9)$ & $(5,7.6,9)$ & $(3,6.3,9)$ & $(5,8.3,9)$ & $(5,8.3,9)$ & $(3,6.3,9)$ & $(3,6.3,9)$ & $(3,5,7)$ & $(3,6.3,9)$ & $(3,6.3,9)$ & $(3,5.6,9)$ \\
\hline$D_{1}$ & $(7,9,9)$ & $(7,9,9)$ & $(3,5,7)$ & $(3,5,7)$ & $(5,7,9)$ & $(5,7,9)$ & $(5,7,9)$ & $(5,7,9)$ & $(7,9,9)$ & $(5,7,9)$ & $(7,9,9)$ & $(5,7,9)$ \\
\hline $\begin{array}{cc}C_{6} & D_{2}\end{array}$ & $(7,9,9)$ & $(5,7,9)$ & $(5,7,9)$ & $(5,7,9)$ & $(7,9,9)$ & $(7,9,9)$ & $(7,9,9)$ & $(7,9,9)$ & $(5,7,9)$ & $(5,7,9)$ & $(5,7,9)$ & $(5,7,9)$ \\
\hline$D_{3}$ & $(7,9,9)$ & $(7,9,9)$ & $(5,7,9)$ & $(5,7,9)$ & $(7,9,9)$ & $(7,9,9)$ & $(7,9,9)$ & $(5,7,9)$ & $(7,9,9)$ & $(3,5,7)$ & $(7,9,9)$ & $(7,9,9)$ \\
\hline$A R$ & $(7,9,9)$ & $(5,8.3,9)$ & $(3,6.3,9)$ & $(3,6.3,9)$ & $(5,8.3,9)$ & $(5,8.3,9)$ & $(5,8.3,9)$ & $(5,7.6,9)$ & $(5,8.3,9)$ & $(3,6.3,9)$ & $(5,8.3,9)$ & $(5,7.6,9)$ \\
\hline$D_{1}$ & $(5,7,9)$ & $(5,7,9)$ & $(3,5,7)$ & $(5,7,9)$ & $(5,7,9)$ & $(3,5,7)$ & $(5,7,9)$ & $(5,7,9)$ & $(3,5,7)$ & $(5,7,9)$ & $(3,5,7)$ & $(5,7,9)$ \\
\hline$D_{2}$ & $(5,7,9)$ & $(3,5,7)$ & $(5,7,9)$ & $(3,5,7)$ & $(3,5,7)$ & $(3,5,7)$ & $(3,5,7)$ & $(3,5,7)$ & $(3,5,7)$ & $(3,5,7)$ & $(3,5,7)$ & $(3,5,7)$ \\
\hline$D_{3}$ & $(3,5,7)$ & $(5,7,9)$ & $(5,7,9)$ & $(5,7,9)$ & $(3,5,7)$ & $(5,7,9)$ & $(3,5,7)$ & $(3,5,7)$ & $(3,5,7)$ & $(3,5,7)$ & $(5,7,9)$ & $(3,5,7)$ \\
\hline$A R$ & $(3,6.3,9)$ & $(3,6.3,9)$ & $(3,6.3,9)$ & $(3,6.3,9)$ & $(3,5.6,9)$ & $(3,5.6,9)$ & $(3,5.6,9)$ & $(3,5.6,9)$ & $(3,5,7)$ & $(3,5.6,9)$ & $(3,5.6,9)$ & $(3,5.6,9)$ \\
\hline$D_{1}$ & $(5,7,9)$ & $(5,7,9)$ & $(5,7,9)$ & $(3,5,7)$ & $(3,5,7)$ & $(5,7,9)$ & $(3,5,7)$ & $(7,9,9)$ & $(5,7,9)$ & $(3,5,7)$ & $(3,5,7)$ & $(3,5,7)$ \\
\hline$C_{8} \quad D_{2}$ & $(3,5,7)$ & $(3,5,7)$ & $(3,5,7)$ & $(5,7,9)$ & $(5,7,9)$ & $(5,7,9)$ & $(5,7,9)$ & $(5,7,9)$ & $(3,5,7)$ & $(5,7,9)$ & $(5,7,9)$ & $(3,5,7)$ \\
\hline$D_{3}$ & $(5,7,9)$ & $(5,7,9)$ & $(3,5,7)$ & $(3,5,7)$ & $(3,5,7)$ & $(3,5,7)$ & $(5,7,9)$ & $(5,7,9)$ & $(3,5,7)$ & $(3,5,7)$ & $(3,5,7)$ & $(5,7,9)$ \\
\hline$A R$ & $(3,6.3,9)$ & $(3,6.3,9)$ & $(3,5.6,9)$ & $(3,5.6,9)$ & $(3,5.6,9)$ & $(3,6.3,9)$ & $(3,6.3,9)$ & $(5,7.6,9)$ & $(3,5.6,9)$ & $(3,6.3,9)$ & $(3,5.6,9)$ & $(3,5.6,9)$ \\
\hline$D_{1}$ & $(5,7,9)$ & $(5,7,9)$ & $(5,7,9)$ & $(5,7,9)$ & $(3,5,7)$ & $(5,7,9)$ & $(5,7,9)$ & $(5,7,9)$ & $(5,7,9)$ & $(1,1,3)$ & $(1,1,3)$ & $(7,9,9)$ \\
\hline$C_{9} \quad D_{2}$ & $(5,7,9)$ & $(5,7,9)$ & $(5,7,9)$ & $(5,7,9)$ & $(5,7,9)$ & $(5,7,9)$ & $(5,7,9)$ & $(5,7,9)$ & $(5,7,9)$ & $(1,1,3)$ & $(1,1,3)$ & $(5,7,9)$ \\
\hline$D_{3}$ & $(5,7,9)$ & $(5,7,9)$ & $(3,5,7)$ & $(5,7,9)$ & $(5,7,9)$ & $(5,7,9)$ & $(5,7,9)$ & $(5,7,9)$ & $(5,7,9)$ & $(1,1,3)$ & $(1,1,3)$ & $(5,7,9)$ \\
\hline$A R$ & $(5,7,9)$ & $(5,7,9)$ & $(3,6.3,9)$ & $(5,7,9)$ & $(3,6.3,9)$ & $(5,7,9)$ & $(5,7,9)$ & $(5,7,9)$ & $(5,7,9)$ & $(1,1,3)$ & $(1,1,3)$ & $(5,7.6,9)$ \\
\hline$D_{1}$ & $(3,5,7)$ & $(3,5,7)$ & $(5,7,9)$ & $(3,5,7)$ & $(5,7,9)$ & $(3,5,7)$ & $(3,5,7)$ & $(3,5,7)$ & $(3,5,7)$ & $(5,7,9)$ & $(5,7,9)$ & $(5,7,9)$ \\
\hline$C_{10} \quad D_{2}$ & $(3,5,7)$ & $(3,5,7)$ & $(3,5,7)$ & $(3,5,7)$ & $(5,7,9)$ & $(3,5,7)$ & $(3,5,7)$ & $(3,5,7)$ & $(3,5,7)$ & $(5,7,9)$ & $(5,7,9)$ & $(5,7,9)$ \\
\hline$D_{3}$ & $(3,5,7)$ & $(3,5,7)$ & $(5,7,9)$ & $(3,5,7)$ & $(5,7,9)$ & $(3,5,7)$ & $(3,5,7)$ & $(3,5,7)$ & $(3,5,7)$ & $(5,7,9)$ & $(5,7,9)$ & $(7,9,9)$ \\
\hline$A R$ & $(3,5,7)$ & $(3,5,7)$ & $(3,6.3,9)$ & $(3,5,7)$ & $(5,7,9)$ & $(3,5,7)$ & $(3,5,7)$ & $(3,5,7)$ & $(3,5,7)$ & $(5,7,9)$ & $(5,7,9)$ & $(5,7.6,9)$ \\
\hline
\end{tabular}

Then we calculate the normalized fuzzy decision matrix for the alternatives by using (7) and (8). Let us take an example, the normalized fuzzy rating of alternative $A_{1}$ for Average claim ratio $\left(C_{1}\right)$ (benefit criteria) is calculated as:

$$
\begin{aligned}
& z_{j}{ }^{*}={ }_{i}^{\max }(9,9,9) \\
& \tilde{p}_{i j}=\left(\frac{7}{9}, \frac{9}{9}, \frac{9}{9}\right)=(0.778,1,1)
\end{aligned}
$$

The normalized fuzzy rating of alternative for Maturity $\left(C_{4}\right)$ (cost criteria) is calculated as:

$$
\begin{aligned}
& x_{j}^{-}={ }_{i}^{\min }(1,1,1) \\
& \tilde{p}_{i j}=\left(\frac{1}{9}, \frac{1}{7.66}, \frac{1}{5}\right)=(0.11,0.1304,0.2)
\end{aligned}
$$

Minimum value for cost criteria and maximum value for benefit criteria is presented in Table 6 that is used for calculating the normalized fuzzy decision matrix. The normalized fuzzy decision matrix is computed for all the possibilities w.r.t every criterion and is presented in Table 7.

Table 6. Minimum value for cost criteria and maximum value for benefit criteria

\begin{tabular}{ccccccccccc}
\hline & $C_{1}$ & $C_{2}$ & $C_{3}$ & $C_{4}$ & $C_{5}$ & $C_{6}$ & $C_{7}$ & $C_{8}$ & $C_{9}$ & $C_{10}$ \\
\hline$x_{j}{ }^{*}$ & 1 & 3 & 1 & 1 & 3 & 3 & 3 & 3 & 1 & 3 \\
$z_{j}{ }^{*}$ & 9 & 9 & 9 & 9 & 9 & 9 & 9 & 9 & 9 & 9
\end{tabular}


Table 7. Normalized fuzzy decision matrix

\begin{tabular}{cccccc}
\hline & $C_{1}$ & $C_{2}$ & $C_{3}$ & $C_{4}$ & $C_{5}$ \\
\hline$A_{1}$ & $(0.78,1,1)$ & $(0.56,0.99,1)$ & $(0.56,0.78,1)$ & $(0.11,0.13,0.20)$ & $(0.56,0.9259,1)$ \\
$A_{2}$ & $(0.78,1,1)$ & $(0.56,0.89,1)$ & $(0.56,0.78,1)$ & $(0.11,0.1765,0.33)$ & $(0.56,0.8519,1)$ \\
$A_{3}$ & $(0.78,1,1)$ & $(0.33,0.70,1)$ & $(0.11,0.74,0.78)$ & $(0.11,0.1579,0.33)$ & $(0.56,0.89,1)$ \\
$A_{4}$ & $(0.56,0.92,1)$ & $(0.56,0.92,1)$ & $(0.33,0.70,1)$ & $(0.11,0.17,0.33)$ & $(0.33,0.70,1)$ \\
$A_{5}$ & $(0.56,0.85,1)$ & $(0.56,0.85,1)$ & $(0.33,0.7037,1)$ & $(0.11,0.13,0.20)$ & $(0.56,0.92,1)$ \\
$A_{6}$ & $(0.56,0.8519,1)$ & $(0.56,0.92,1)$ & $(0.33,0.7037,1)$ & $(0.11,0.17,0.33)$ & $(0.56,0.92,1)$ \\
$A_{7}$ & $(0.33,0.62,1)$ & $(0.56,0.85,1)$ & $(0.56,0.92,1)$ & $(0.11,0.15,0.33)$ & $(0.33,0.70,1)$ \\
$A_{8}$ & $(0.33,0.7037,1)$ & $(0.56,0.85,1)$ & $(0.11,0.33,0.55)$ & $(0.11,0.19,0.33)$ & $(0.33,0.37,1)$ \\
$A_{9}$ & $(0.56,0.85,1)$ & $(0.56,0.77,1)$ & $(0.33,0.70,1)$ & $(0.11,0.13,0.20)$ & $(0.33,0.55,0.77)$ \\
$A_{10}$ & $(0.33,0.62,1)$ & $(0.33,0.70,1)$ & $(0.56,0.85,1)$ & $(0.14,0.23,1)$ & $(0.33,0.70,1)$ \\
$A_{11}$ & $(0.11,0.48,0.77)$ & $(0.33,0.7,1)$ & $(0.11,0.23,0.55)$ & $(0.11,0.13,0.20)$ & $(0.33,0.70,1)$ \\
$A_{12}$ & $(0.11,0.40,0.77)$ & $(0.56,0.85,1)$ & $(0.33,0.70,1)$ & $(0.11,0.12,0.20)$ & $(0.33,0.66,1)$ \\
\hline & $C_{6}$ & $C_{7}$ & $C_{8}$ & & $C_{9}$ \\
\hline$A_{1}$ & $(0.33,0.33,0.42)$ & $(0.33,0.70,1)$ & $(0.33,0.70,1)$ & $(0.56,0.77,1)$ & $(0.33,0.55,0.77)$ \\
$A_{2}$ & $(0.33,0.36,0.60)$ & $(0.33,0.7037,1)$ & $(0.33,0.70,1)$ & $(0.56,0.77,1)$ & $(0.33,0.55,0.77)$ \\
$A_{3}$ & $(0.33,0.47,1)$ & $(0.33,0.70,1)$ & $(0.33,0.62,1)$ & $(0.33,0.70,1)$ & $(0.33,0.70,1)$ \\
$A_{4}$ & $(0.33,0.47,1)$ & $(0.33,0.7037,1)$ & $(0.33,0.62,1)$ & $(0.56,0.77,1)$ & $(0.33,0.55,0.78)$ \\
$A_{5}$ & $(0.33,0.36,0.60)$ & $(0.33,0.62,1)$ & $(0.33,0.62,1)$ & $(0.33,0.70,1)$ & $(0.56,0.77,1)$ \\
$A_{6}$ & $(0.33,0.36,0.60)$ & $(0.33,0.62,1)$ & $(0.33,0.70,1)$ & $(0.56,0.78,1)$ & $(0.33,0.55,0.77)$ \\
$A_{7}$ & $(0.33,0.30,0.60)$ & $(0.33,0.62,1)$ & $(0.33,0.70,1)$ & $(0.56,0.77,1)$ & $(0.33,0.56,0.78)$ \\
$A_{8}$ & $(0.33,0.39,0.60)$ & $(0.33,0.62,1)$ & $(0.56,0.85,1)$ & $(0.56,0.77,1)$ & $(0.33,0.56,0.77)$ \\
$A_{9}$ & $(0.33,0.36,0.60)$ & $(0.33,0.56,0.77)$ & $(0.33,0.62,1)$ & $(0.56,0.77,1)$ & $(0.33,0.56,0.77)$ \\
$A_{10}$ & $(0.33,0.47,1)$ & $(0.33,0.62,1)$ & $(0.33,0.70,1)$ & $(0.11,0.11,0.33)$ & $(0.56,0.78,1)$ \\
$A_{11}$ & $(0.33,0.36,0.60)$ & $(0.33,0.62,1)$ & $(0.33,0.62,1)$ & $(0.11,0.33)$ & $(0.56,0.78,1)$ \\
$A_{12}$ & $(0.33,0.39,0.60)$ & $(0.33,0.62,1)$ & $(0.33,0.62,1)$ & $(0.56,0.85,1)$ & $(0.56,0.85,1)$ \\
\hline & & & & &
\end{tabular}

The next step is computing the normalized fuzzy decision matrix for all the alternatives by using (9). The values of that are present in Table 4 and the values of that is present in Table 5 are required to compute the weighted normalized fuzzy decision matrix. Let us take an example, the weighted normalized fuzzy assessment of alternative $A_{1}$ for Average claim ratio $\left(C_{1}\right)$ is given by:

$$
\widetilde{W C} C_{i j}=(0.778,1,1)(7,9,9)=(5.4444,9,9)
$$

Similarly, we computed the weighted normalized fuzzy decision matrix for all the alternatives w.r.t each criterion and that is presented in Table 8.

Table 8. Weighted normalized fuzzy decision matrix

\begin{tabular}{|c|c|c|c|c|c|}
\hline & $C_{1}$ & $C_{2}$ & $C_{3}$ & $C_{4}$ & $C_{5}$ \\
\hline$A_{1}$ & $(5.44,9,9)$ & $(2.778,7.0988,9)$ & $(3.89,7,9)$ & $(0.56,1.0870,1.80)$ & $(2.78,7.7160,9)$ \\
\hline$A_{2}$ & $(5.44,9,9)$ & $(2.78,6.5309,9)$ & $(3.89,7,9)$ & $(0.56,1.4706,3)$ & $(2.78,7.0988,9)$ \\
\hline$A_{3}$ & $(5.44,9,9)$ & $(1.67,5.3951,9)$ & $(0.78,3.6667,7)$ & $(0.56,1.3158,3)$ & $(2.78,7.0988,9)$ \\
\hline$A_{4}$ & $(3.89,8.3333,9)$ & $(2.78,7.0988,9)$ & $(2.33,6.3333,9)$ & $(0.56,1.4706,3)$ & $(1.67,5.8642,9)$ \\
\hline$A_{5}$ & $(3.89,7.6667,9)$ & $(2.78,6.5309,9)$ & $(2.33,6.3333,9)$ & $(0.56,1.0870,1.80)$ & $(2.78,7.7160,9)$ \\
\hline$A_{6}$ & $(3.89,7.6667,9)$ & $(2.78,7.0988,9)$ & $(2.33,6.3333,9)$ & $(0.56,1.4706,3)$ & $(2.78,7.7160,9)$ \\
\hline$A_{7}$ & $(2.33,5.6667,9)$ & $(2.78,6.5309,9)$ & $(3.89,8.33,9)$ & $(0.56,1.3158,3)$ & $(1.67,5.862,9)$ \\
\hline$A_{8}$ & $(2.33,6.3333,9)$ & $(2.78,6.5309,9)$ & $(0.78,3,5)$ & $(0.56,1.3158,3)$ & $(1.67,5.8642,9)$ \\
\hline$A_{9}$ & $(3.89,7.6667,9)$ & $(2.78,5.9630,9)$ & $(2.33,6.3333,9)$ & $(0.56,1.0870,1.80)$ & $(1.67,4.6296,7)$ \\
\hline$A_{10}$ & $(2.33,5.6667,9)$ & $(1.67,5.3951,9)$ & $(3.89,7.6667,9)$ & $(0.73,1.9231,9)$ & $(1.67,5.8642,9)$ \\
\hline$A_{11}$ & $(0.78,4.3333,7)$ & $(1.67,5.3951,9)$ & $(0.78,2.3333,5)$ & $(0.56,1.087,1.80)$ & $(1.67,5.8642,9)$ \\
\hline \multirow[t]{2}{*}{$A_{12}$} & $(0.78,3.6667,7)$ & $(2.78,6.5309,9)$ & $(2.33,6.3333,9)$ & $(0.56,1,1.8000)$ & $(1.67,5.2469,9)$ \\
\hline & $C_{6}$ & $C_{7}$ & $C_{8}$ & $C_{9}$ & $C_{10}$ \\
\hline$A_{1}$ & $(2.33,3,3.8571)$ & $(1.67,5.3951,9)$ & $(1,4.4568,9)$ & $(1.67,4.4074,9)$ & $(1,2.78,5.4444)$ \\
\hline$A_{2}$ & $(2.33,3.2400,5.40)$ & $(1.67,5.3951,9)$ & $(1,4.4568,9)$ & $(1.67,4.4074,9)$ & $(1,2.78,5.4444)$ \\
\hline$A_{3}$ & $(2.33,4.2632,9)$ & $(1.67,5.3951,9)$ & $(1,3.9877,9)$ & $(1,3.9877,9)$ & $(1,3.5185,7)$ \\
\hline$A_{4}$ & $(2.33,4.2632,9)$ & $(1.67,5.3951,9)$ & $(1,3.9877,9)$ & $(1.67,4.4074,9)$ & $(1,2.78,5.4444)$ \\
\hline$A_{5}$ & $(2.33,3.2400,5.40)$ & $(1.67,4.8272,9)$ & $(1,3.9877,9)$ & $(1,3.9877,9)$ & $(1.67,3.8889,7)$ \\
\hline$A_{6}$ & $(2.33,3.2400,5.40)$ & $(1.67,4.8272,9)$ & $(1,4.4568,9)$ & $(1.67,4.4074,9)$ & $(1,2.78,5.4444)$ \\
\hline$A_{7}$ & $(2.33,3.2400,5.40)$ & $(1.67,4.8272,9)$ & $(1,4.4568,9)$ & $(1.67,4.4074,9)$ & $(1,2.78,5.4444)$ \\
\hline$A_{8}$ & $(2.33,3.5217,5.40)$ & $(1.67,4.8272,9)$ & $(1.67,5.3951,9)$ & $(1.67,4.4074,9)$ & $(1,2.78,5.4444)$ \\
\hline$A_{9}$ & $(2.33,3.2400,5.40)$ & $(1.67,4.2593,7)$ & $(1,3.9877,9)$ & $(1.67,4.4074,9)$ & $(1,2.78,5.4444)$ \\
\hline$A_{10}$ & $(2.33,4.2632,9)$ & $(1.67,4.8272,9)$ & $(1,4.4568,9)$ & $(0.33,0.6296,3)$ & $(1.67,3.8889,7)$ \\
\hline$A_{11}$ & $(2.33,3.2400,5.40)$ & $(1.67,4.8272,9)$ & $(1,3.9877,9)$ & $(0.33,0.6296,3)$ & $(1.67,3.8889,7)$ \\
\hline$A_{12}$ & $(2.33,3.5217,5.40)$ & $(1.67,4.8272,9)$ & $(1,3.9877,9)$ & $(1.67,4.8272,9)$ & $(1.67,4.2593,7)$ \\
\hline
\end{tabular}


Then we compute the FPIS and FNIS by using (10) and (11). For an example, the FPIS $\left(F^{+}\right)$and FNIS $\left(F^{-}\right)$for average claim ratio $\left(C_{1}\right)$ is given by: $F^{+}=(9,9,9)$ and $\left.F^{-}=(0.7778,0.7778,0.7778)\right)$ Similarly, we calculate the FPIS and FNIS for all the criteria that is presented in Table 9.

\begin{tabular}{|c|c|c|}
\hline \multicolumn{2}{|c|}{$\operatorname{FPIS}\left(F^{+}\right)$} & $F P I S\left(F^{-}\right)$ \\
\hline$C_{1}$ & $(9,9,9)$ & $(0.78,0.7778,0.7778)$ \\
\hline$C_{2}$ & $(9,9,9)$ & $(1.67,1.6667,1.6667)$ \\
\hline$C_{3}$ & $(9,9,9)$ & $(0.78,0.7778,0.7778)$ \\
\hline$C_{4}$ & $(9,9,9)$ & $(0.56,0.5556,0.5556)$ \\
\hline$C_{5}$ & $(9,9,9)$ & $(1.67,1.6667,1.6667)$ \\
\hline$C_{6}$ & $(9,9,9)$ & $(2.33,2.3333,2.3333)$ \\
\hline$C_{7}$ & $(9,9,9)$ & $(1.67,1.6667,1.6667)$ \\
\hline$C_{8}$ & $(9,9,9)$ & $(1,1,1)$ \\
\hline$C_{9}$ & $(9,9,9)$ & $(0.33,0.3333,0.3333)$ \\
\hline$C_{10}$ & $(7,7,7)$ & $(1,1,1)$ \\
\hline
\end{tabular}

Now we computed the distance $v_{t}($.$) for every possibility from FPIS ( ) and FNIS ( ) by using (3),$ (12), and (13). For an example the distances $\left(v_{t} A_{1}{ }^{+}\right)$and $\left(v_{t} A_{1}^{-}\right)$of alternative $A_{1}$ for Average claim ratio are computed as follows:

$$
\begin{aligned}
& \left(v_{t}, A_{1}^{+}\right)=\sqrt{\frac{1}{3}\left[(5.4444-9)^{2}+(9-9)^{2}+(9-9)^{2}\right]}=2.0528 \\
& \left(v_{t}, A_{1}^{-}\right)=\sqrt{\frac{1}{3}\left[(5.4444-0.7778)^{2}+(9-0.7778)^{2}+(9-0.7778)^{2}\right]}=7.2338
\end{aligned}
$$

This way we calculate the distances for all the criteria and all the possibilities that are depicted in Tables 10-11.

Table 10. Distance $v_{i}\left(A_{i}, F^{+}\right)$for alternatives

\begin{tabular}{rrrrrrrrrrrrr}
\hline & $v_{t}, A_{1}{ }^{+}$ & $v_{t}, A_{2}{ }^{+}$ & $v_{t}, A_{3}{ }^{+}$ & $v_{t}, A_{4}{ }^{+}$ & $v_{t}, A_{5}{ }^{+}$ & $v_{t}, A_{6}{ }^{+}$ & $v_{t}, A_{7}{ }^{+}$ & $v_{t}, A_{8}{ }^{+}$ & $v_{t}, A_{9}{ }^{+}$ & $v_{t}, A_{10}{ }^{+}$ & $v_{t}, A_{11}{ }^{+}$ & $v_{t}, A_{12}{ }^{+}$ \\
\hline$C_{1}$ & 2.05 & 2.05 & 2.05 & 2.99 & 3.04 & 3.04 & 4.30 & 4.14 & 3.04 & 4.30 & 5.57 & 5.77 \\
$C_{2}$ & 3.75 & 3.86 & 4.71 & 3.75 & 3.86 & 3.75 & 3.86 & 3.86 & 3.99 & 4.71 & 4.71 & 3.86 \\
$C_{3}$ & 3.16 & 3.16 & 5.77 & 4.14 & 4.14 & 4.14 & 2.97 & 6.31 & 4.14 & 3.04 & 6.53 & 4.14 \\
$C_{4}$ & 7.86 & 7.39 & 7.44 & 7.39 & 7.86 & 7.39 & 7.44 & 7.44 & 7.86 & 6.29 & 7.86 & 7.89 \\
$C_{5}$ & 3.66 & 3.75 & 3.75 & 4.60 & 3.66 & 3.66 & 4.60 & 4.60 & 5.06 & 4.60 & 4.60 & 4.75 \\
$C_{6}$ & 5.96 & 5.49 & 4.72 & 4.72 & 5.49 & 5.49 & 5.49 & 5.39 & 5.49 & 4.72 & 5.49 & 5.39 \\
$C_{7}$ & 4.71 & 4.71 & 4.71 & 4.71 & 4.87 & 4.87 & 4.87 & 4.87 & 5.17 & 4.87 & 4.87 & 4.87 \\
$C_{8}$ & 5.31 & 5.31 & 5.45 & 5.45 & 5.45 & 5.31 & 5.31 & 4.71 & 5.45 & 5.31 & 5.45 & 5.45 \\
$C_{9}$ & 4.99 & 4.97 & 5.45 & 4.99 & 5.45 & 4.99 & 4.99 & 4.99 & 4.99 & 7.77 & 7.77 & 4.87 \\
$C_{10}$ & 4.33 & 4.33 & 4.05 & 4.33 & 3.56 & 4.33 & 4.33 & 4.33 & 4.33 & 3.56 & 3.56 & 3.46 \\
\hline
\end{tabular}

\begin{tabular}{|c|c|c|c|c|c|c|c|c|c|c|c|c|}
\hline & $v_{t}, A_{1}^{-}$ & $v_{t}, A_{2}^{-}$ & $v_{t}, A_{3}{ }^{-}$ & $v_{t}, A_{4}^{-}$ & $v_{t}, A_{5}{ }^{-}$ & $v_{t}, A_{6}{ }^{-}$ & $v_{t}, A_{7}^{-}$ & $v_{t}, A_{8}{ }^{-}$ & $v_{t}, A_{9}^{-}$ & $v_{t}, A_{10}{ }^{-}$ & $v_{t}, A_{11}{ }^{-}$ & $v_{t}, A_{12}{ }^{-}$ \\
\hline$C_{1}$ & 7.23 & 7.2339 & 7.29 & 6.69 & 6.44 & 6.44 & 5.59 & 5.7991 & 6.44 & 5.59 & 4.13 & 3.96 \\
\hline$C_{2}$ & 5.30 & 5.1210 & 4.74 & 5.30 & 5.12 & 5.30 & 5.12 & 5.1210 & 4.94 & 4.74 & 4.74 & 5.12 \\
\hline$C_{3}$ & 6.21 & 6.2183 & 3.96 & 5.79 & 5.79 & 5.79 & 6.69 & 2.7547 & 5.79 & 6.44 & 2.59 & 5.79 \\
\hline$C_{4}$ & 0.78 & 1.5069 & 1.47 & 1.50 & 0.78 & 1.50 & 1.47 & 1.4780 & 0.78 & 4.93 & 0.78 & 0.76 \\
\hline$C_{5}$ & 5.52 & 5.3079 & 5.30 & 4.87 & 5.52 & 5.52 & 4.87 & 4.8784 & 3.52 & 4.87 & 4.87 & 4.71 \\
\hline$C_{6}$ & 0.96 & 1.8463 & 4.00 & 4.00 & 1.84 & 1.84 & 1.84 & 1.8988 & 1.84 & 4.00 & 1.84 & 1.89 \\
\hline$C_{7}$ & 4.74 & 4.74 & 4.74 & 4.74 & 4.61 & 4.61 & 4.61 & 4.61 & 3.42 & 4.61 & 4.61 & 4.61 \\
\hline$C_{8}$ & 5.03 & 5.03 & 4.93 & 4.93 & 4.93 & 5.03 & 5.03 & 5.28 & 4.93 & 5.03 & 4.93 & 4.93 \\
\hline$C_{9}$ & 5.58 & 5.58 & 5.44 & 5.58 & 5.44 & 5.58 & 5.58 & 5.58 & 5.58 & 1.54 & 1.54 & 5.68 \\
\hline$C_{10}$ & 2.76 & 2.76 & 3.75 & 2.76 & 3.86 & 2.76 & 2.76 & 2.76 & 2.76 & 3.86 & 3.86 & 3.96 \\
\hline
\end{tabular}

Table 11. Distance $v_{i}\left(A_{i}, F^{-}\right)$for alternatives

Then we calculate the distances $v_{i}^{+}$and $v_{i}^{-}$using (12) and (13). Let us take an example, the distances $v_{i}{ }^{+}$and $\left(v_{i}{ }^{-}\right)$of alternative $A_{1}$ for Average claim ratio $\left(C_{1}\right)$ are computed as follows:

$$
\left(v_{i}^{+}\right)=45.839 \text { and }\left(v_{i}^{-}\right)=44.1547
$$


We compute the closeness coefficient $\left(S_{i}\right)$ buy using distances $v_{i}^{+}$and $v_{i}^{-}$for all the alternatives that is given by (14). Let us take an example the $S_{i}$ of alternative $A_{1}$ is given by:

$$
S_{i}=\frac{44.1547}{44.1547+45.8394}=0.4906
$$

Similarly, we compute for all alternatives, that is presented in Table 12.

Table 12. Closeness coefficients of the alternatives

\begin{tabular}{cllllllllllll}
\hline & $A_{1}$ & $A_{2}$ & $A_{3}$ & $A_{4}$ & $A_{5}$ & $A_{6}$ & $A_{7}$ & $A_{8}$ & $A_{9}$ & $A_{10}$ & $A_{11}$ & $A_{12}$ \\
\hline$v_{i}{ }^{-}$ & 44.15 & 45.36 & 45.61 & 46.21 & 44.37 & 44.42 & 43.59 & 40.17 & 40.0463 & 45.67 & 33.94 & 41.45 \\
$v_{i}{ }^{+}$ & 45.83 & 45.08 & 48.09 & 47.09 & 47.42 & 47.01 & 48.19 & 50.68 & 49.5671 & 49.20 & 56.45 & 50.49 \\
$S_{i}$ & 0.49 & 0.50 & 0.48 & 0.49 & 0.48 & 0.48 & 0.47 & 0.44 & 0.4469 & 0.48 & 0.37 & 0.45 \\
\hline
\end{tabular}

Finally, we rank the alternatives by comparing the $C C_{i}$ value, that is given in Table 12 . We find that LIC $\left(A_{2}\right)>\operatorname{SBI}\left(A_{4}\right)>\operatorname{ICICI}\left(A_{1}\right)>\operatorname{HDFC}\left(A_{3}\right)>\operatorname{BAJAJ} \operatorname{ALIANZ}\left(A_{6}\right)>\operatorname{MAX}\left(A_{5}\right)>\operatorname{KOTAK} \operatorname{MAHINDRA}$ $\left(A_{10}\right)>$ BHARTI AXA $\left(A_{7}\right)>\operatorname{AVIVA}\left(A_{12}\right)>\operatorname{RELIANCE}\left(A_{9}\right)>$ AEGON RELIGARE $\left(A_{8}\right)>$ CANARA HSBC $\left(A_{11}\right)$. So LIC $\left(A_{2}\right)$ is recommended as best insurance company for an online term plan. Ranking of all the alternatives are presented in Figure. 2.

\section{Ranking of alternatives}

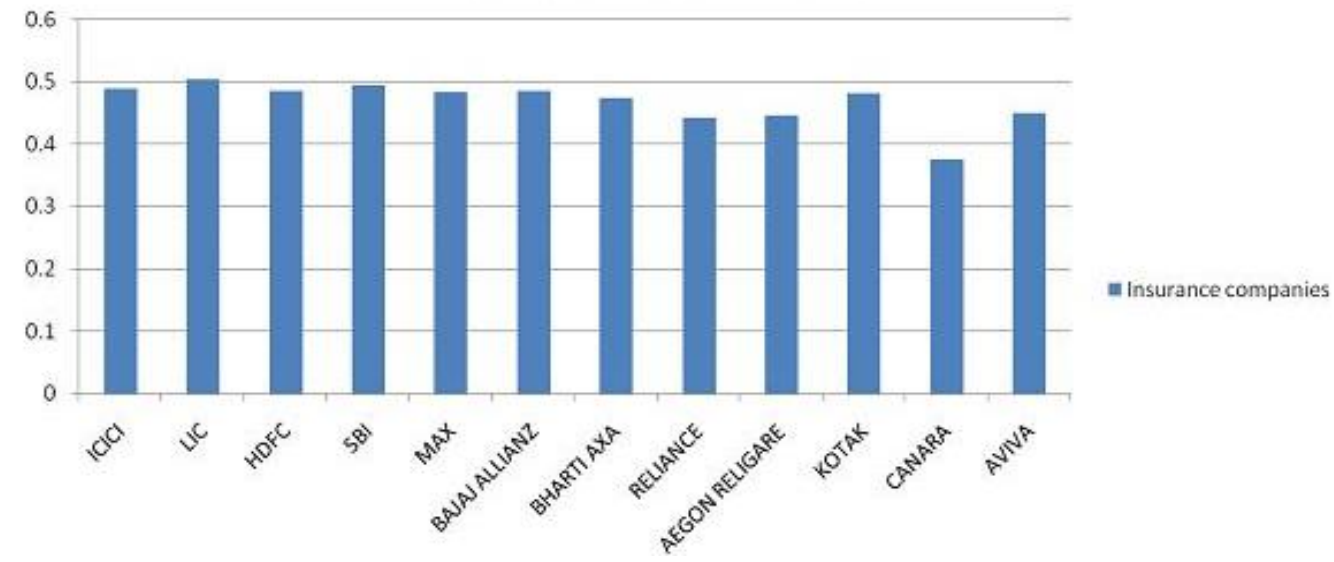

Figure 2. Ranking of insurance companies

\subsection{Sensitivity analysis}

We conducted a SA to find the influence of weights of criteria on the best insurance company choosing for purchasing an online term policy. The numbers of 25 experiments were conducted, which are presented in Table 13. In the first two experiments, all of the criteria weight we are assigned to $(7,9,9)$ and $(5,7,9)$, that is presented in Table 13. In third and fourth experiment, we set the weight of criterion ${ }_{1}=(7,9,9)$ and the rest of criteria have weight $=(5,7,9)$ and $(3,5,7)$ respectively. In fifth experiment, we set the weight of criterion $C_{1}=(5,7,9)$ and the rest of criteria have weight $=(3,5,7)$. In experiments $6-9$, we set the weight of all criteria $=(7,9,9)$ except the cost criteria $C_{4}$ and $C_{6}$. The weights of $C_{4}$ and $C_{6}$ for the experiments 6-9 are respectively $(5,7,9),(3,5,7),(1,3,5)$ and $(1,1,3)$. In experiments $10-13$, we set the weight of all criteria $=(5,7,9)$ except the cost criteria $C_{4}$ and $C_{6}$. The weights of $C_{4}$ and $C_{6}$ for the experiments $10-13$ are respectively $(7,9,9),(3,5,7),(1,3,5)$ and $(1,1,3)$. In experiment 14 and 15 , we set the weight of all criteria $=(3,5,7)$ except the cost criteria $C_{4}$ and $C_{6}$. The weights of $C_{4}$ and $C_{6}$ for the experiments 14 and15 are respectively $(1,3,5)$ and $(1,1,3)$. In experiment 16 , we set the weights of criteria $C_{1}$ and $C_{2}=(7,9,9)$, and all other criteria weights $=(5,7,9)$. In experiment 17 , we set the weights of criteria $C_{1}, C_{2}$ and $C_{3}=(7,9$, $9)$, and all other criteria weights $=(5,7,9)$. In experiments $18-20$, all criteria have weights $(3,5,7),(1,3,5)$ and $(1,1,3)$ respectively. In experiment 21 and 22 , we set the weight of all criteria $=(3,5,7)$ except the cost criteria $\mathrm{C}_{4}$ and $\mathrm{C}_{6}$. The weights of $\mathrm{C}_{4}$ and $\mathrm{C}_{6}$ for the experiments 21 and 22 are respectively $(7,9,9)$ and $(5,7,9)$. In experiment 23 , we set the weight of criterion $C_{1}=(3,5,7)$ and all other criteria weights $=(1,3,5)$. In 
experiment 24 , we set the weights of criteria $C_{1}$ and $C_{2}=(3,5,7)$ and all other criteria weights $=(1,3,5)$. In experiment 25 , we set the weights of criteria $C_{1}, C_{2}$ and $C_{3}=(3,5,7)$ and the rest of criteria have weight $=(1$, $3,5)$. Out of 25 experiments, LIC $\left(\mathrm{A}_{2}\right)$ is selected as best insurance company in first 17 experiments. However, $\mathrm{SBI}\left(\mathrm{A}_{4}\right)$ is selected as best insurance company in last 8 experiments.

Table 13. Experiment for sensitivity analysis

\begin{tabular}{cllllllllllll}
\hline Exp. No. & $A_{1}$ & $A_{2}$ & $A_{3}$ & $A_{4}$ & $A_{5}$ & $A_{6}$ & $A_{7}$ & $A_{8}$ & $A_{9}$ & $A_{10}$ & $A_{11}$ & $A_{12}$ \\
\hline 1 & 0.51 & 0.52 & 0.50 & 0.51 & 0.51 & 0.51 & 0.49 & 0.46 & 0.46 & 0.49 & 0.38 & 0.47 \\
2 & 0.46 & 0.47 & 0.47 & 0.47 & 0.46 & 0.46 & 0.45 & 0.43 & 0.43 & 0.46 & 0.37 & 0.44 \\
3 & 0.47 & 0.49 & 0.48 & 0.48 & 0.47 & 0.47 & 0.46 & 0.43 & 0.43 & 0.46 & 0.37 & 0.44 \\
4 & 0.47 & 0.48 & 0.48 & 0.48 & 0.47 & 0.47 & 0.45 & 0.43 & 0.44 & 0.46 & 0.37 & 0.44 \\
5 & 0.46 & 0.47 & 0.47 & 0.47 & 0.46 & 0.46 & 0.45 & 0.43 & 0.43 & 0.46 & 0.37 & 0.43 \\
6 & 0.51 & 0.52 & 0.50 & 0.51 & 0.50 & 0.50 & 0.49 & 0.46 & 0.46 & 0.49 & 0.38 & 0.47 \\
7 & 0.53 & 0.54 & 0.512 & 0.52 & 0.52 & 0.52 & 0.50 & 0.47 & 0.47 & 0.49 & 0.39 & 0.49 \\
8 & 0.55 & 0.55 & 0.52 & 0.53 & 0.53 & 0.53 & 0.52 & 0.49 & 0.49 & 0.49 & 0.40 & 0.50 \\
9 & 0.57 & 0.57 & 0.53 & 0.54 & 0.55 & 0.55 & 0.53 & 0.50 & 0.50 & 0.49 & 0.41 & 0.52 \\
10 & 0.46 & 0.48 & 0.47 & 0.48 & 0.46 & 0.47 & 0.46 & 0.43 & 0.43 & 0.46 & 0.36 & 0.44 \\
11 & 0.48 & 0.49 & 0.47 & 0.48 & 0.48 & 0.48 & 0.47 & 0.44 & 0.44 & 0.46 & 0.37 & 0.45 \\
12 & 0.49 & 0.50 & 0.48 & 0.49 & 0.49 & 0.49 & 0.48 & 0.45 & 0.45 & 0.46 & 0.38 & 0.47 \\
13 & 0.51 & 0.51 & 0.49 & 0.50 & 0.50 & 0.50 & 0.49 & 0.46 & 0.46 & 0.46 & 0.39 & 0.48 \\
14 & 0.473 & 0.47 & 0.471 & 0.47 & 0.47 & 0.47 & 0.46 & 0.44 & 0.45 & 0.43 & 0.38 & 0.45 \\
15 & 0.49 & 0.49 & 0.48 & 0.48 & 0.48 & 0.48 & 0.47 & 0.45 & 0.45 & 0.45 & 0.39 & 0.46 \\
16 & 0.48 & 0.49 & 0.48 & 0.49 & 0.48 & 0.48 & 0.46 & 0.44 & 0.44 & 0.47 & 0.37 & 0.45 \\
17 & 0.49 & 0.50 & 0.48 & 0.49 & 0.48 & 0.48 & 0.47 & 0.44 & 0.44 & 0.47 & 0.37 & 0.45 \\
18 & 0.45 & 0.46 & 0.46 & 0.46 & 0.45 & 0.45 & 0.45 & 0.42 & 0.42 & 0.45 & 0.37 & 0.43 \\
19 & 0.43 & 0.44 & 0.44 & 0.45 & 0.44 & 0.44 & 0.43 & 0.41 & 0.41 & 0.44 & 0.37 & 0.42 \\
20 & 0.39 & 0.40 & 0.41 & 0.41 & 0.40 & 0.40 & 0.40 & 0.38 & 0.37 & 0.41 & 0.34 & 0.39 \\
21 & 0.44 & 0.45 & 0.45 & 0.46 & 0.44 & 0.44 & 0.43 & 0.41 & 0.41 & 0.45 & 0.36 & 0.42 \\
22 & 0.43 & 0.45 & 0.45 & 0.46 & 0.44 & 0.44 & 0.43 & 0.41 & 0.41 & 0.45 & 0.36 & 0.42 \\
23 & 0.44 & 0.45 & 0.46 & 0.46 & 0.45 & 0.45 & 0.44 & 0.42 & 0.42 & 0.45 & 0.37 & 0.42 \\
24 & 0.45 & 0.46 & 0.46 & 0.46 & 0.45 & 0.45 & 0.44 & 0.43 & 0.42 & 0.45 & 0.37 & 0.43 \\
25 & 0.46 & 0.47 & 0.46 & 0.47 & 0.46 & 0.46 & 0.45 & 0.42 & 0.43 & 0.46 & 0.37 & 0.43 \\
\hline
\end{tabular}

\section{CONCLUSION}

Since several companies offer a wide variety of policies, a recommender system which works on multi-criteria is devised to rank the LI policies and rank them. The customers can be recommended insurance based on the ranks. Increase in data resulted in techniques to extract important data from a large amount of information. A fuzzy method is more suitable to handle a large amount of information as well as imprecise data. In this paper, a fuzzy MCDM (TOPSIS) has been applied to rank the insurance companies in India for purchasing an online policy. The experimental results showed that LIC has been selected as the best insurance company for an online term plan followed by SBI. The results of the sensitivity analysis showed LIC has been selected as the best insurance company in the first 17 experiments out of 25 . Since the data are collected from the expert opinion, it may vary from expert to expert, so it can be considered as the limitation of this proposed model. In future, we will extend this work by applying other fuzzy methods or Pythagorean fuzzy method and bio-inspired methods to solve this problem of insurance selection.

\section{REFERENCES}

[1] M. Pratama, P. P. Angelov, E. Lughofer, and M. J. Er, "Parsimonious random vector functional link network for data streams," Information Sciences, vol. 430, pp. 519-537, 2018.

[2] M. Pratama, J. Lu, and G. Zhang, "Evolving type-2 fuzzy classifier," IEEE Transactions on Fuzzy Systems, vol. 24, no. 3, pp. 574-589, 2015.

[3] M. Aruldoss, T. M. Lakshmi, and V. P. Venkatesan, "A survey on multi criteria decision making methods and its applications," American Journal of Information Systems, vol. 1, no. 1, pp. 31-43, 2013.

[4] R. Mishra, "A fuzzy approach for multi criteria decision making in web recommendation system for e-commerce," In 2013 Eleventh International Conference on ICT and Knowledge Engineering, IEEE, pp. 1-4, 2013.

[5] G. Adomavicius, N. Manouselis, and Y. Kwon, "Multi-criteria recommender systems," In Recommender Systems Handbook, Springer, Boston, MA, pp. 769-803, 2011.

[6] L. A. Zadeh, "Fuzzy sets," Information and Control, vol. 8, no. 3, pp. 338-353, 1965.

[7] M. D. Hurd and K. McGarry, "Medical insurance and the use of health care services by the elderly," Journal of Health Economics, vol. 16, no. 2, pp. 129-154, 1997.

[8] C. Zopounidis, "Multicriteria decision aid in financial management," European Journal of Operational Research, vol. 119, no. 2, pp. 404-415, 1999.

[9] G. Adomavicius and Y. Kwon, "New recommendation techniques for multicriteria rating systems," IEEE Intelligent Systems, vol. 22, no. 3, pp. 48-55, 2007. 
[10] Z. Xu and M. Xia, "On distance and correlation measures of hesitant fuzzy information," International Journal of Intelligent Systems, vol. 26, no. 5, pp. 410-425, 2011.

[11] D. Ho and M. Sherris, "Portfolio selection for insurance linked securities: An application of multiple criteria decisions making," Working Papers No. 201203, ARC Centre of Excellence in Population Ageing Research (CEPAR), Australian School of Business, University of New South Wales, 2012.

[12] Z. Xu and M. Xia, "Hesitant fuzzy entropy and cross-entropy and their use in multiattribute decision-making," International Journal of Intelligent Systems, vol. 27, no. 9, pp. 799-822, 2012.

[13] Y. Jain, "Economic reforms and World economic crisis: Changing Indian life insurance market place," ISOR Journal of Business and Management, vol. 8, no. 1, pp. 106-115, 2013.

[14] B. Farhadinia, "A novel method of ranking hesitant fuzzy values for multiple attribute decision-making problems," International Journal of Intelligent Systems, vol. 28, no. 8, pp. 752-767, 2013.

[15] S. Jagdale, A. Jagdale, K. Venkataraman, and V. B. Gupta, "Multi-criterion decision approach in ranking of money back insurance policies," 18 National Conference on Mapping for Excellence Challenges Ahead (Management), pp. 534-538, 2014.

[16] S. Khodamoradi, A. Safari, and R. Rahimi, "A hybrid multi-criteria model for insurance companies rating," International Business Research, vol. 7, no. 6, pp. 150-163, 2014.

[17] H. Garg, "A new generalized Pythagorean fuzzy information aggregation using Einstein operations and its application to decision making," International Journal of Intelligent Systems, vol. 31, no. 9, pp. 886-920, 2016.

[18] K. Y. Shen, S. K. Hu, and G. H. Tzeng, "Financial modeling and improvement planning for the life insurance industry by using a rough knowledge-based hybrid MCDM model," Information Sci., vol. 375, pp. 296-313, 2017.

[19] A. R. Torbati and M. K. Sayadi, "A new approach to investigate the performance of insurance branches in Iran using best-worst method and fuzzy inference system," Journal of Soft Computing and Decision Support Systems, vol. 5, no. 4, pp. 13-18, 2018.

[20] F. Chiclana, R. Kumar, M. Mittal, M. Khari, J. M. Chatterjee, and S. W. Baik, "ARM-AMO: an efficient association rule mining algorithm based on animal migration optimization," Knowledge-Based Systems, vol. 154, pp. 68-80, 2018.

[21] J. M. Chatterjee, S. Ghatak, R. Kumar, and M. Khari, "BitCoin exclusively informational money: a valuable review from 2010 to 2017," Quality \& Quantity, vol. 52, no. 5, 2037-2054, 2018.

[22] Q. Zhao, P. H. Tsai, and J. L. Wang, "Improving financial service innovation strategies for enhancing china's banking industry competitive advantage during the fintech revolution: A Hybrid MCDM model," Sustainability, vol. 11 , no. 5 , p. $1419,2019$.

[23] S. Jha, R. Kumar, J. M. Chatterjee, and M. Khari, "Collaborative handshaking approaches between internet of computing and internet of things towards a smart world: a review from 2009-2017," Telecommunication Systems, vol. 70, no. 4, 617-634, 2019.

[24] S. Jha, R. Kumar, J. M. Chatterjee, M. Khari, N. Yadav, and F. Smarandache, "Neutrosophic soft set decision making for stock trending analysis," Evolving Systems, vol. 10, no. 4, 621-627, 2019.

[25] P. H. Son, S. Jha, R. Kumar, and J. M. Chatterjee, "Governing mobile virtual network operators in developing countries," Utilities Policy, vol. 56, 169-180, 2019.

[26] H. K. Tripathy, B. R. Acharya, R. Kumar, and J. M. Chatterjee, "Machine learning on big data: A developmental approach on societal applications," In Big Data Processing Using Spark in Cloud, Springer, pp. 143-165, 2019.

[27] A. Choudhuri, J. M. Chatterjee, and S. Garg, "Internet of Things in healthcare: A brief overview," In Internet of Things in Biomedical Engineering, Academic Press, pp. 131-160, 2019.

[28] A. Kumar, J. M. Chatterjee, and V. G. Díaz, "A novel hybrid approach of SVM combined with NLP and probabilistic neural network for email phishing," International Journal of Electrical and Computer Engineering, vol. 10, no. 1, pp. 486-493, 2020.

[29] M. Abbas and Z. Chergui, "The impact of using new significant reference point with TOPSIS methods: study and application," International Journal of Information and Decision Sciences, vol. 11, no. 2, 95-115, 2019.

[30] A. Fahmi, M. Aslam, F. A. A. Almahdi, and F. Amin, "New type of cancer patients based on triangular cubic hesitant fuzzy TOPSIS method," International Journal of Biomathematics, vol. 13, no. 1, p. 2050002, 2020.

[31] M. Akram, W. A. Dudek, and F. Ilyas, "Group decision-making based on pythagorean fuzzy TOPSIS method," International Journal of Intelligent Systems, vol. 34, no. 7, 1455-1475, 2019.

[32] S. Hussain, M. Aslam, F. Amin, S. Abdullah, and A. Fahmi, "Trapezoidal linguistic cubic fuzzy TOPSIS method and application in a group decision making program,” J. of Intelligent Systems, vol. 29, no 1, pp. 1283-1300, 2019.

[33] A. Muruganantham and G. M. Gandhi, "Framework for social media analytics based on multi-criteria decision making (MCDM) model," Multimedia Tools and Applications, vol. 79, no. 5, 3913-3927, 2020.

[34] K. Lakiotaki, S. Tsafarakis, and N. Matsatsinis, "UTA-Rec: a recommender system based on multiple criteria analysis," In Proceedings of the 2008 ACM Conference on Recommender Systems, pp. 219-226, 2008.

[35] A. Awasthi and S. S. Chauhan, "A hybrid approach integrating affinity diagram, AHP and fuzzy TOPSIS for sustainable city logistics planning," Applied Mathematical Modelling, vol. 36, no. 2, pp. 573-584, 2012.

[36] T. L. Saaty, "The analytic hierarchy process," McGraw-Hill. New York, 324, 1980.

[37] P. Upadhyay, "Satisfaction of the policy holders protection in insurance sector: A case study," International Journal of Advanced Research in Computer Science and Software Engineering, vol. 3, no. 2, pp.32-40, 2013.

[38] Insurance Advisory Committee, "The Gazette of India extraordinary part-III-Section 4," Insurance Regulatory and $\begin{array}{lllll}\text { Development of } & \text { India, } 2019 . & \text { Anline]. }\end{array}$ https://www.irdai.gov.in/ADMINCMS/cms/NormalData_Layout.aspx?page=PageNo1641\&mid=5.1. 
[39] M. Sevkli, S. Zaim, A. Turkyilmaz, and M. Satir, "An application of fuzzy Topsis method for supplier selection," In International Conference on Fuzzy Systems, IEEE, pp. 1-7, 2010.

[40] A. Memariani, A. Amini, and A. Alinezhad, "Sensitivity analysis of simple additive weighting method (SAW): the results of change in the weight of one attribute on the final ranking of alternatives," Journal of Optimization in Industrial Engineering, vol. 4, no. 4, pp. 13-18, 2009.

[41] M. Pratama, J. Lu, E. Lughofer, G. Zhang, and M. J. Er, "An incremental learning of concept drifts using evolving type-2 recurrent fuzzy neural networks," IEEE Transactions on Fuzzy Systems, vol. 25, no. 5, pp. 1175-1192, 2016.

\section{BIOGRAPHIES OF AUTHORS}

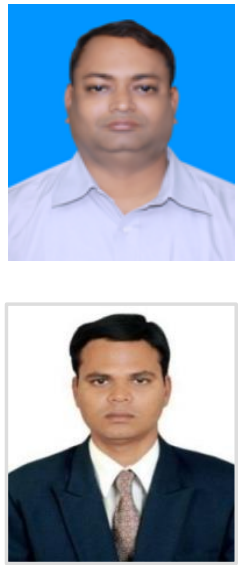

Chinmaya Ranjan Pattanaik, presently working as Asst Prof in Computer Science and Engineerig at Ajaya Binay Institute of Technology Cuttack, Awareded Ph. D from KIIT University in 2017 and has 4 and half years of Industrial experiences in IBM Mainframes before joining Academics on December 2000.

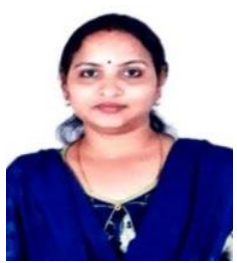

Sachi Nandan Mohanty, received his Postdoc from IIT Kanpur in the year 2019 and Ph.D. from IIT Kharagpur, India in the year 2014, with MHRD scholarship from Govt of India. He has recently joined as Associate Professor in the Department of Computer Science \& Engineering at ICFAI Foundation for Higher Education Hyderabad. His research areas include Data mining, Big Data Analysis, Cognitive Science, Fuzzy Decision Making, Brain-Computer Interface, Cognition, and Computational Intelligence. Prof. S N Mohanty has received 3 Best Paper Awards during his Ph. D at IIT Kharagpur from International Conference at Benjing, China, and the other at International Conference on Soft Computing Applications organized by IIT Rookee in the year 2013 .

Sarita Mohanty Working as Assistant professor in department of Centre for Post Graduate Studies, OUAT, Govt. of Odisha. She did Mtech in Computer Sc at Berhampur University, Odisha, india. She has more than 18 years of teaching with 5 years Industry experience. Her research interest lies in the area of Machine Learning, Theory of Computation, Compiler Design, Data Mining, Artificial Intelligence etc.

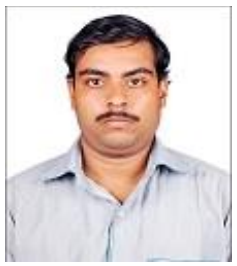

Jyotir Moy Chatterjee is currently working as an Assistant Professor of IT department at Lord Buddha Education Foundation (Asia Pacific University of Technology \& Innovation), Kathmandu, Nepal. Prior to this he has worked as an Assistant Professor at CSE department at GD Rungta College of Engineering \& Technology (CSVTU), Bhilai, India. He has completed M. Tech from Kalinga Institute of Industrial Technology, Bhubaneswar, Odisha and B. Tech in Computer Science \& Engineering from Dr. MGR Educational \& Research Institute, Chennai. His research interests include the Cloud Computing, Big Data, Privacy Preservation, Data Mining, Internet of Things, Machine Learning, Blockchain Technology. He is member of various professional societies and international conferences.

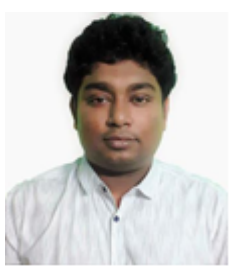

Biswajit Jana, completed his M. Tech from KIIT University, Bhubaneswar in the year 2015. He has joined as Research Assistant under TEQIP-III and pursuing PhD in the Department of Computer Science \& Engineering at MAKAUT, WB. His research areas include Soft Computing, Decision Making, Machine Learning, Computational Intelligence and Computational Biology.

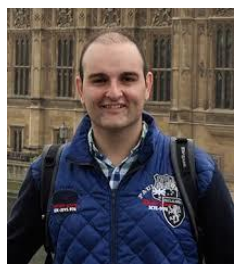

Vicente García-Díaz is an associate professor in the Computer Science Department of the University of Oviedo. He has a PhD from the University of Oviedo in computer engineering. His research interests include model-driven engineering, domain specific languages, technology for learning and entertainment, project risk management, software development processes and practices. He has graduated in Prevention of Occupational Risks and is a Certified Associate in Project Management through the Project Management Institute. 